\title{
EDITORIAL
}

\section{Conflictividad social}

Estos primeros meses de 1987 se han caracterizado por fuertes dosis de conflictividad social. Se han manifestado con sus diferentes reivindicaciones los estudiantes - de bachillerato y universitarios-, los médicos y sanitarios, los jornaleros del campo, los agricultores, los obreros industriales y del sector servicios. Los motivos han sido varios, pero nos vamos a concentrar en tres, que creemos los más importantes y significativos.

Están en primer lugar las reivindicaciones salariales. Con muy buen acuerdo, el Gobierno da prioridad en su política económica a la lucha antiinflacionaria: terminar el año 1987 con una inflación en torno al 5 por 100, medida aquella por el Indice de Precios al Consumo. Para lograrlo uno de los pivotes lo constituve la moderación salarial; por eso recomienda que las revisiones de sueldos en convenios colectivos se muevan en los aledaños de ese 5 por 100.

Opinamos, como lo hemos dado a entender, que esta estrategia es básicamente correcta, la única alternativa sana y viable para la salida de la crisis económica y la creación de empleo. Asil lo confirman las opiniones de los mejores expertos nacionales e internacionales; asilo avala la experiencia de los países industriales de nuestro ámbito occidental que mejor están sorteando la crisis y preparando el futuro.

Minusvalorar la inflación nos llevaria a una creciente pérdida de competitividad en las empresas españolas, a fuertes desequilibrios de nuestra balanza de pagos, al cierre de innumerables empresas, a la destrucción de empleo, al aumento del paro.

¿Están los sindicatos técnicamente bien asesorados o proceden de manera irresponsable? ¿Acaso muestran una solidaridad, pero sólo a corto plazo y con los que disponen de un empleo estable? ¿Dónde está la solidaridad con los parados de ahora y del futuro? ¿Tal vez se dejan llevar simplemente de afanes proselitistas? ¿O es que CCOO está haciendo sencillamente oposición política al servicio de los intereses del PCE?

En cualquier caso opinamos que la actual política económica del Gobierno socialista es fundamentalmente válida, incluso para los intereses generales de los trabajadores en el conjunto del corto, medio y largo plazo. Le deseamos, pues, simplemente firmeza y continuidad. 


\section{Editorial}

En segundo término se pone en tela de juicio la reconversión industrial. Diriamos aquialgo parecido a lo anterior: la reconversión industrial es totaly absolutamente necesaria. Para poder competir en el futuro no sólo en los mercados internacionales, sino también en los nacionales, dentro de un régimen de libertad económica. Pensemos que ni Japón, ni Estados Unidos, ni Europa paran o cejan en su modernización económica. $\gamma$ que nosotros mismos compramos sin misericordia; es decir, compramos a quien nos ofrece algo en mejores condiciones de precio y calidad. Aunque se hundan innumerables empresas a la cola de la modernización económica. Esto nos sucedería a nosotros sin reconversión industrial.

Unicamente pensamos particularmente que cuando la reconversión lleva consigo reducción de plantillas, se debe ejecutar ésta de la manera más humana posible; teniendo muy en cuenta los intereses y los derechos adquiridos de los afectados. Esto se logra, a nuestro juicio, vinculando los despidos a jubilaciones anticipadas, seguro de desempleo y, sobre todo, reindustrialización, creación de puestos alternativos de trabajo.

En tercer lugar se demanda en los conflictos diálogo y concertación con los poderes públicos. Asílo pidieron los estudiantes, asilos agricultores, asilo reclaman los sindicatos. En este punto creemos existe una grave responsabilidad por parte del Gobierno. Refugiado en su mayoría absoluta, con un cierto desprecio por la oposición parlamentaria, creemos ha caído demasiado en la tentación del "ordeno y mando", sin contar suficientemente con las opiniones de las fuerzas sociales, sin abrir suficientemente el diálogo y la concertación con los intereses agrupados, más o menos corporativos. Y la calle, y los intereses corporativos, como era de temer, se han estado sublevando.

Opinamos que, a estas alturas, ya no basta con la democracia politica parlamentaria formal y con sus meras reglas de juego. Estimamos que, además, es necesaria, porque la calle lo pide, una sociedad bien estructurada en asociaciones entre el individuo y el Estado. Una sociedad asíque, connaturalmente, pide protagonismo a través del diálogo y la concertación con los poderes del Estado. Es el neo-corporatismo. En él destacan países como Austria, Suecia, Noruega, Finlandia, Holanda, Alemania Occidental; paises que brillan hoy, no por casualidad, por la paz social la prosperidad general y los bajísimos porcentajes de paro.

El Estado tendrá que permitir, a esos intereses agrupados, penetrar algo en las esferas del poder politico, a través de la concertación, pero obtendrá en el intercambio una mayor gobernabilidad general del país, vias de desagüe para los conflictos insurgentes y una atenuación de la 


\section{Editorial}

virulencia reivindicativa de los intereses agrupados. Creemos merece la pena la permuta.

Esperamos que la lección de estos primeros meses de 1987 sea bien aprendida para un próximo futuro. 